IZA DP No. 9203

Performance Standards and Employee Effort:

Evidence from Teacher Absences

Seth Gershenson

July 2015 


\title{
Performance Standards and Employee Effort: Evidence from Teacher Absences
}

\author{
Seth Gershenson \\ American University \\ and IZA
}

Discussion Paper No. 9203

July 2015

IZA

P.O. Box 7240

53072 Bonn

Germany

\author{
Phone: +49-228-3894-0 \\ Fax: +49-228-3894-180 \\ E-mail: iza@iza.org
}

\begin{abstract}
Any opinions expressed here are those of the author(s) and not those of IZA. Research published in this series may include views on policy, but the institute itself takes no institutional policy positions. The IZA research network is committed to the IZA Guiding Principles of Research Integrity.

The Institute for the Study of Labor (IZA) in Bonn is a local and virtual international research center and a place of communication between science, politics and business. IZA is an independent nonprofit organization supported by Deutsche Post Foundation. The center is associated with the University of Bonn and offers a stimulating research environment through its international network, workshops and conferences, data service, project support, research visits and doctoral program. IZA engages in (i) original and internationally competitive research in all fields of labor economics, (ii) development of policy concepts, and (iii) dissemination of research results and concepts to the interested public.
\end{abstract}

IZA Discussion Papers often represent preliminary work and are circulated to encourage discussion. Citation of such a paper should account for its provisional character. A revised version may be available directly from the author. 


\section{ABSTRACT \\ Performance Standards and Employee Effort: Evidence from Teacher Absences*}

The 2001 No Child Left Behind Act (NCLB) increased accountability pressure in U.S. public schools by threatening to impose sanctions on Title-1 schools that failed to make Adequate Yearly Progress (AYP) in consecutive years. Difference-in-difference estimates of the effect of failing AYP in the first year of NCLB on teacher effort in the subsequent year suggest that on average, teacher absences in North Carolina fell by about $10 \%$ and the probability of being absent 15 or more times fell by about $20 \%$. Reductions in teacher absences were driven by within-teacher increases in effort.

JEL Classification: J45, J48, J22, I2

Keywords: performance standards, employee effort, teacher absences, accountability, NCLB

Corresponding author:

Seth Gershenson

School of Public Affairs

American University

4400 Massachusetts Avenue, NW

Washington, DC 20016-8070

USA

E-mail: gershens@american.edu.

\footnotetext{
* The author is thankful for financial support from the W.E. Upjohn Institute's Early Career Research Grant program and an American University Faculty Research Support Grant. Opinions reflect those of the author and not necessarily those of the granting agencies. Participants at the 2014 APPAM Fall Conference, 2015 AEA Annual Meeting, 2015 WEAI Pacific Rim Conference, 2015 SOLE/EALE Joint Conference, and George Mason University Microeconomics Policy Seminar provided helpful comments. Ashlyn Holeyfield, Stephen Holt, and Katie Vinopal provided excellent research assistance. Any remaining errors are my own.
} 


\section{INTRODUCTION}

The public-sector accountability movement originated in the U.S. in the 1980s under the premise that performance can — and should — be measured in the public and non-profit sectors (Figlio \& Kenny, 2009). Recent reforms in numerous areas of the public sector, including public education, have focused on using objective, observable measures of performance to reward efficiency and responsiveness and to hold units accountable (Heckman, Heinrich, \& Smith, 2011; Heinrich \& Marschke, 2010). In the context of K-12 public education, high-stakes (i.e., evidence- or test-based) accountability policies aim to evaluate teachers, schools, or students on the basis of students' performance on standardized exams (Ladd, 1996). Such policies now play a prominent role in both state and federal U.S. education policy (Figlio \& Loeb, 2011). The rationale for such policies is that attaching incentives to students' performance on standardized exams will alleviate the principal-agent problem inherent in the relationship between stakeholders and schools and improve student outcomes as a result (Figlio \& Loeb, 2011; Heinrich \& Marschke, 2010). More generally, education economists argue that properly-aligned incentives can increase student achievement and decrease the costs of public education (e.g., Hanushek, 1994; Hoxby, 2007).

The proliferation of state-level accountability policies in the 1990s and the 2001 passage of the Federal No Child Left Behind Act (NCLB) reflect education policymakers' enthusiasm for such policies and have provided researchers with numerous contexts in which to investigate the impact of such policies on student achievement. Figlio and Loeb (2011), Figlio and Ladd (2008), and Hout and Elliot (2011) provide thorough reviews of this literature, which generally finds modest but statistically significant effects of about 0.1 to 0.3 test-score standard deviations (SD). For example, Carnoy and Loeb (2002) and Hanushek and Raymond (2005) exploit cross-state 
variation in the strength of high-stakes accountability policies and find positive effects on student test scores. Similarly, Dee and Jacob (2011) compare the effect of NCLB on student achievement in states that had pre-existing high-stakes accountability systems similar to NCLB to NCLB's effect in states that did not, arguing that states without preexisting high-stakes accountability policies were "treated more intensely" by NCLB, and find that NCLB improved math test scores in "treated" states by about $0.2 \mathrm{SD}$.

However, critics of high-stakes accountability policies worry that these test-score gains are illusory and reflect strategic responses by schools rather than true learning gains. For example, high-stakes accountability policies' relatively narrow focus on standardized test scores, usually in math and reading, may cause teachers and schools to divert resources and instructional time away from non-tested topics and skills that are valued by stakeholders and important for students' long-run socioeconomic success (Baker et al., 2010). Indeed, some evidence suggests that teachers "teach to the test," as Jacob (2005) uses an interrupted time series research design to find an effect of a high-stakes accountability policy in Chicago Public Schools of about 0.3 SD on high-stakes tests but no effect on low-stakes National Assessment of Educational Progress (NAEP) test scores. Similarly, Reback, Rockoff, and Schwartz (2014) find evidence that NCLB accountability pressure caused schools to shift time away from non-tested subjects like science and social studies. Even thoughtfully designed "growth-based" policies that account for initial performance levels are subject to "ratchet effects," or dynamic distortions caused by actors making current decisions with the intent of manipulating future targets (Macartney, 2014). There is also evidence of nefarious unintended consequences of high-stakes accountability policies. For example, schools have prevented low-performing students from taking the standardized tests on which accountability policies are based either by reclassifying certain students as non-tested 
special-education students (Cullen \& Reback, 2006) or suspending them on test days (Figlio 2006). There is even evidence of outright teacher cheating (Jacob \& Levitt, 2003).

As a result, the mechanisms through which high-stakes accountability policies affect students' academic achievement are not entirely understood, but have implications for the design of future education policies. Rouse et al. (2013) provide evidence that accountability pressure in Florida affected instructional policy and practice, and that such changes explain a nontrivial percentage of corresponding achievement gains. Increased teacher effort is another potential mechanism through which high-stakes accountability policies might improve student achievement, as teachers are among the most important school-provided educational inputs (Ahn, 2013; Hanushek \& Rivkin, 2010; Jacob, 2013; Rockoff \& Turner, 2010). Teacher attendance is one measure of teacher effort, or teacher productivity, that affects student achievement (Ahn, 2013; Clotfelter et al., 2009; Das et al., 2007; Duflo, Hanna, \& Ryan, 2012; Herrmann \& Rockoff, 2012; Miller, Murnane, \& Willet, 2008). Moreover, teacher attendance is positively correlated with both principals' ratings of teachers and teachers' value-added scores (Jacob \& Walsh, 2011). Teacher absences are costly in other ways: the substitute teachers necessitated by teacher absences are financially costly (Roza, 2007) and teacher absences create negative externalities, as Bradley, Green, and Leeves (2007) find that teachers' absences are affected by the attendance of their peers. The current study contributes to our understanding of the mechanisms through which consequential accountability policies affect student achievement and, more generally, how public-sector employees respond to the threat of sanctions associated with performance standards by examining how, if at all, failing to make Adequate Yearly Progress (AYP) in the first year of NCLB affected teacher absence rates. 
The direction of the effect of high-stakes accountability policies on teacher absences is theoretically ambiguous, as such policies might affect teachers in two ways. ${ }^{1}$ On the one hand, the incentives provided by such policies are intended to increase teacher effort (Ahn, 2013; Hansen, 2009). Viewing attendance as a type of employee effort, high-stakes accountability policies are hypothesized to decrease teacher absences. ${ }^{2}$ Indeed, Jacob (2013) uses a differencein-difference (DD) research design to show that a policy change in Chicago Public Schools that granted principals the ability to dismiss probationary teachers resulted in a significant decrease in probationary teachers' absences. To the extent that accountability pressure raises job security concerns (Reback et al., 2014), teachers might increase their attendance rates in an effort to keep their jobs. Similarly, principals are known to influence teacher attendance (e.g., Gaziel, 2004; Imants \& Van Zoelen, 1995), and might implore teachers to increase attendance in response to the threat of performance-based sanctions. Finally, the threat of being labelled a "failing school" might directly increase teacher effort, as public employees are often motivated by non-pecuniary recognition (i.e., symbolic value) of working in high performing institutions (Heinrich, 2007).

On the other hand, the stress and pressure placed on teachers by high-stakes accountability policies might increase the psychic costs associated with teaching and lead to higher rates of teacher absences as a result (Clotfelter et al., 2009; Ose, 2005; Johansson \& Palme, 1996). It is well documented that teachers report feeling more stress (Daly \& Chrispeels, 2005) and less autonomy (Luna \& Turner, 2001) after the implementation of consequential

\footnotetext{
${ }^{1}$ The direction of the effect of accountability policies on teacher turnover is similarly theoretically ambiguous (e.g., Clotfelter et al., 2004; Feng et al., 2010). Online Appendix A formalizes this ambiguity in the context of a daily labor supply model.

${ }^{2}$ See Ahn (2013), Hansen (2009), and Jacob (2013) for further justification of the use of teacher absences as a proxy for teacher effort and productivity.
} 
accountability policies. Indeed, Pain Reduction Models suggest that employees reduce job dissatisfaction by being absent more often (Gaziel, 2004).

Which of these two hypothesized effects dominates is an empirical question that I address in the current study using statewide administrative longitudinal data on public primary school teachers in North Carolina. Specifically, I employ a DD-style identification strategy using data that spans the first two years of NCLB. The treatment is failing to make AYP in the first year of NCLB, which "turned on" the threat of sanctions for failing to make AYP in two consecutive years. The main results suggest that the threat of sanctions following failure to make AYP in the initial year of NCLB caused a robust, statistically significant decrease in teacher absences that cannot be explained by preexisting differential trends in treated schools nor by changes in the composition of treated schools' teaching staffs. These effects are arguably practically significant, representing 10\% declines in teacher absences. Moreover, these effects likely represent lower bounds of the effect of performance standards on teacher absences, as schools that made AYP in 2003 (the control group) were under pressure to improve as well.

The paper proceeds as follows: Section 2 describes the relevant institutional details regarding teacher absences and accountability policy in North Carolina. Section 3 specifies the econometric model and identification strategy. Section 4 describes the data and section 5 presents the results. Section 6 concludes.

\section{BACKGROUND}

\section{Teacher Absences in North Carolina}

Teachers in North Carolina's public schools are permitted to take a limited number of absences per year, though not without incurring some personal costs. The current study focuses 
on two particular types of absences_-sick and personal leave — as these are the most relevant sources of teacher absences during the school year (Ahn, 2013; Clotfelter et al., 2009). Teachers accrue sick leave at a rate of one day per month. For this reason, the cost of sick days is decreasing in teacher experience. Unused sick days can be redeemed at retirement for additional pension benefits, which makes using accumulated sick days costly to teachers. Teachers can also use more than their allotted number of sick days at a cost of $\$ 50$ per absence and are similarly charged \$50 per day of personal leave. Clotfelter et al. (2009) show that between 1995 and 2004 the average public-school classroom teacher in North Carolina took about seven sick days and one personal leave day per academic year. As expected, absences are slightly more common among more experienced teachers. The authors also examine the predictors of teacher absences, finding that absences are more common among teachers in elementary schools and schools serving low-income students. Teacher absences are less common among teachers who have a masters degree, graduated from a selective undergraduate institution, or are National Board Certified (Clotfelter et al., 2009).

\section{Preexisting ABC Accountability Policy}

North Carolina first implemented the ABC accountability policy at the start of the 19961997 academic year (Macartney, 2014). Henceforth, academic years are referred to by the year of the spring semester. The ABC policy is notable in that it focuses on achievement growth in addition to achievement levels, as schools are thought to have relatively more influence on the former. Achievement is measured by student performance on end-of-grade tests in math and reading administered near the end of the school year in grades 3 through 8 . The tests are state mandated, aligned with state standards, criterion referenced, and vertically aligned. Schools that 
fail to make expected growth are labeled as either "no recognition" or "low performing," depending on whether or not at least $50 \%$ of students score at or above grade level. Schools that make expected growth are labeled as such, and schools that exceed expected growth by $10 \%$ or more are classified as "high growth." However, there are no direct sanctions for failing to meet growth requirements. Ahn (2013) carefully describes how these classifications are made.

Teachers in "high" and "expected" growth schools receive annual bonuses of \$1,500 and $\$ 750$, respectively. Ahn (2013) exploits the resulting discontinuity in award receipt to examine how teachers' effort responds to incentives. Intuitively, Ahn finds a U-shaped relationship between teacher absences and the probability of receiving a bonus, with highest effort occurring when bonus receipt is uncertain. ${ }^{3}$ Similarly, Clotfelter et al. (2004) point out that while ABC's focus on growth provides an arguably more valid measure of school performance, it is not perfect, as there may be numerous barriers to growth in low-performing schools. For this reason, teachers may attempt to transfer out of schools with low baseline achievement levels. The authors estimate the effect of $\mathrm{ABC}$ on teacher turnover using a DD strategy that compares turnover in low- and high-performing schools, before and after the implementation of $\mathrm{ABC}$, and find that $\mathrm{ABC}$ increased turnover probabilities by about $25 \%$ in low-performing schools. However, given the current study's focus on the introduction of NCLB, it is worth stressing that the determinants of AYP and expected growth are mostly unrelated and nearly half of schools that make expected growth fail AYP, and vice versa (Ahn, 2013). Moreover, in sensitivity analyses I show that the main results are robust to controlling for schools' standing under ABC.

\footnotetext{
${ }^{3}$ The only other investigation of the effect of a consequential accountability policy on teacher attendance that I am aware of is a secondary analysis in the online appendix of Rockoff and Turner (2010), which finds no significant effect of a school's receipt of a failing grade on average teacher absences in the school.
} 


\section{The 2001 No Child Left Behind Act (NCLB)}

NCLB extended North Carolina's existing ABC accountability policy in three ways. First, it required that all schools make adequate yearly progress (AYP), which differed from existing $\mathrm{ABC}$ growth requirements by requiring that schools meet percent proficient, student attendance, and test-participation thresholds both overall and for specific subgroups of the student population. Second, NCLB mandated that states publish "school report cards" containing information on schools' performance levels and AYP status. Third, NCLB mandated additional sanctions on Title-1 schools that failed to make AYP in consecutive years. The current study focuses on Title-1 schools, as such schools comprise the majority of North Carolina's public primary schools and the threat of sanctions is particularly salient in such schools. The identification strategy described below exploits the fact that Title-1 schools that failed to make AYP in 2003, the first year of NCLB, were under considerably more pressure in 2004 than Title1 schools that made AYP in 2003. This idea is similar to that used by Chakrabarti (2014), who also considers 2003 a "pre-program” year, and Ahn and Vigdor (2014), who exploit variation in schools' AYP histories. ${ }^{4}$ The current study focuses on data from 1997 through 2004 for two reasons. First, data on teacher absences are unreliable after 2004 (Ahn, 2013). Second, the determination of AYP became more complex after 2004 due to NCLB waivers and "Safe Harbor" exemptions (e.g., Polikoff \& Wrabel, 2013).

Title 1 was a component of the original ESEA that was reinstituted by NCLB, which provides federal funds to schools in proportion to the number of low-income students attending

\footnotetext{
${ }^{4}$ These studies utilize regression discontinuity (RD) designs that exploit schools" "closeness" to the AYP threshold. Rockoff and Turner (2010) use a similar RD strategy to estimate the effect of school grades on student achievement in NYC public schools. Online Appendix B presents RD estimates that are qualitatively similar to the preferred difference-in-difference estimates reported in the main text.
} 
the school (Gordon, 2008). This money can be used to cover the cost of tutoring, after-school, and summer programs that reinforce the school's standard curriculum. When NCLB was first implemented, it mandated that Title-1 schools that failed to make AYP for two consecutive years enter Program Improvement (PI). PI is a five-year process of steadily increasing consequences that culminates with the drastic restructuring of the school (e.g., the school is reinvented as a charter, taken over by the state, or replaces a majority of the staff). Therefore, the passage of NCLB placed pressure on all Title-1 schools and this pressure increased in severity in Title-1 schools that failed AYP in the first year of NCLB. Accordingly, DD estimates of the effect of failing AYP on teacher absences likely underestimate the total effect of NCLB on teacher absences, as the policy placed pressure on all schools in 2004, even those that did not fail AYP in 2003 (Fuller \& Ladd, 2013).

\section{ECONOMETRIC MODEL AND IDENTIFICATION STRATEGY}

The baseline analytic sample contains the 1997 through 2004 academic years. 2003 was the first year of NCLB and thus the first year that AYP was computed. The threatened sanctions associated with failing AYP in two consecutive years make 2004 was the first year that could possibly send a school to the PI program. Accordingly, the preferred model of teacher $i$ 's absences ( $A$, in levels), while in school $s$ and year $t$, is a difference-in-difference (DD) specification similar to the baseline specification in Jacob (2013). Formally,

$$
A_{i s t}=\gamma_{t}+\tau d 04_{t} \times \text { Failed } 03_{s}+\beta X_{i s t}+\theta_{s}+\varepsilon_{i s t},
$$

where $\gamma$ is a year fixed effect $(\mathrm{FE}) ; d 04$ is a binary indicator equal to one in 2004 and zero

otherwise; Failed 03 is a binary indicator equal to one if school $s$ failed to make AYP in 2003 and zero otherwise; $X$ is a vector of observed teacher and school characteristics including the 
teacher's National Board Certification, experience, educational attainment, selectivity of undergraduate institution, race, and gender and the school's total enrollment, fulltime equivalent teachers, student-teacher ratio, percent of enrollment eligible for free or reduced price lunch, and percent of enrollment that is non-white; $\theta$ is a school $\mathrm{FE}$, and $\varepsilon$ is an idiosyncratic error term. The elements of $X$ and the school FE are consistent with the broad categories of theoretical determinants of employee absences identified by Ichino and Maggi (2000) and Bradley et al. (2007). ${ }^{5}$ Conditioning on $X$ and $\theta$ tend to improve the precision of estimates of $\tau$, the DD estimate of the effect of the increase in accountability pressure caused by the failure to make AYP in the inaugural year of NCLB, which is the primary parameter of interest. However, the main results are robust to omitting $X$ and $\theta$ from equation (1).

Importantly, the school FE subsume the time-invariant Failed 03 indicator usually included in a DD specification and imply that comparisons are made within, as opposed to between, schools. Still, the possibility of pre-existing school-specific trends is a threat to identification, as teacher absences in schools that failed to make AYP in 2003 may have been trending in systematically different ways than teacher absences in schools that did make AYP. I test for the presence of pre-existing differential trends using an augmented event-study version of (1) that includes a full set of year $\times$ Failed 03 interactions. Similarly, I relax the parallel slopes assumption by augmenting equation (1) to include linear or quadratic school time trends. Teacher FE or lagged teacher absences can also be added to the model to control for the nonrandom sorting of teachers to schools and distinguish within-teacher behavioral changes from changes in the compositions of schools' teaching forces. Finally, I test for heterogeneous effects by teacher

\footnotetext{
${ }^{5}$ Specifically, the categories are individual background, school background (i.e., locality or contextual effects), and group (social) interaction effects whereby group norms affect individual absence rates. Ose (2005) also provides theoretical and empirical support for the hypothesis that workplace environments might affect employee absences.
} 
characteristics by augmenting equation (1) to include a full set of interaction terms. The baseline models are estimated by OLS and standard errors are clustered at the school level. ${ }^{6}$ A number of additional sensitivity analyses are conducted and discussed in section 5 .

\section{DATA}

The main analyses are of primary (K-5) public school teachers who taught in Title-1 schools in North Carolina between 1997 and 2004. These longitudinal teacher-level administrative data are maintained and provided by the North Carolina Education Research Data Center (NCERDC). ${ }^{7}$ The NCERDC data contain administrative records on teachers' absences per pay period, race, gender, experience, National Board Certification, educational attainment, and undergraduate institution attended. The baseline analytic sample is restricted to teacher-years in which these variables, and school-level information on total enrollment, student demographics, and fulltime equivalent teachers are observed in the first two years of NCLB. There are 28,456 such teacher-years.

Following previous research on teacher absences in North Carolina (Ahn, 2013;

Clotfelter et al., 2009), total annual teacher absences are calculated as the sum of absences coded as either sick or personal leave. The third broad class of absence, vacation leave, typically occurs during days that school is not in session and is thus excluded from the operationalized definition of teacher absences. Column (1) of table 1 reports summary statistics for the baseline analytic sample. The average teacher was absent about eight times per year, which is consistent with

\footnotetext{
${ }^{6}$ Teacher absences are not actually a count variable because the data contain fractions of absences, so negative binomial and Poisson regressions are not appropriate.

${ }^{7}$ See http://www.childandfamilypolicy.duke.edu/project_detail.php?id=35.
} 
previous research and largely driven by sick leave. About ten percent of teachers were absent 15 or more times in a given year.

The SD of nine indicates substantial variation in teacher absences. To better understand the variation in teachers' absences I decompose the total variation into within -school, -school year, and -teacher variation by estimating "within-unit" SD. I do so by computing the SD of the residuals from regressions of teacher absences on sets of school, school-by-year, and teacher FE, respectively. The within-school and within-school year SD reported in column 1 for the baseline analytic sample are quite close to the overall SD, indicating that most of the total variation in teacher absences occurs within, as opposed to between, schools. Moreover, about $94 \%$ of the total variation occurs within school-years. Importantly, these results suggest that there is sufficient within-school and within-school year variation to identify the preferred school-FE specifications. The within-teacher SD constitutes 80 percent of the overall SD, suggesting that there is enough within-teacher variation to implement teacher FE estimators.

The analytic sample is approximately evenly split across tested (grades 3 through 5) and non-tested (Kindergarten and grades 1 and 2) grades. About one quarter of teachers had earned a Masters degree and a trivial percentage had earned a doctorate. Teachers who reported less than a four-year degree are excluded from the sample. Four percent of teachers attended a selective undergraduate institution, where selectivity is coded as a dichotomous variable based on ratings from Barron's Profiles of American Colleges. Specifically, the selective indicator equals one if Barron's rated the institution as "most" or "highly" selective, and zero otherwise. Eleven percent of teachers were National Board Certified and the average teacher had about 14 years of experience teaching in North Carolina. The analytic sample is predominantly female and white.

I also test for heterogeneity by teacher effectiveness using value-added measures (VAMs). The VAMs are generated by using NCERDC student-teacher matched student-level 
administrative data on end-of grade math test scores to estimate standard lag-score value-added models. Accordingly, VAMs are available for teachers who taught at least two years in fourth or fifth grade. ${ }^{8}$ Math scores are used because the literature on teacher effectiveness typically finds greater variation in teachers' effects on math than on reading (e.g., Hanushek \& Rivkin, 2010). Importantly, I estimate VAMs for all teachers who taught in 2003 and 2004, not only those for whom absence data are available. I then record the quartile of the full distribution of teacher effectiveness in which teachers in the baseline analytic sample are located.

Column (2) of table 1 reports summary statistics for the subsample of the baseline analytic sample for whom VAMs are available. The VAM subsample summarized in column 2 closely resembles the baseline sample summarized in column 1, with two notable exceptions: the VAM subsample contains more tested-grade and male teachers. Intuitively, the former is due to VAM scores being unavailable for teachers in non-tested grades. Tested-grade teachers do not comprise the entire VAM subsample, however, because some teachers transitioned to a tested grade after being in a non-tested grade in 2004. Brummet et al. (2015) and Ost (2014) show that grade switching is fairly common among primary school teachers. The latter is due to men being more likely to teach in higher grades, which in the primary school context are also the tested grades.

\section{RESULTS}

\section{Main Results}

Table 2 reports estimates of the DD model shown in equation (1). These models condition on teacher covariates, school FE, and time-varying school covariates. Column 1

\footnotetext{
${ }^{8}$ See Online Appendix C for a complete description of the value-added model and estimation.
} 
reports the DD estimate of the preferred baseline specification that is linear in teacher absences. The point estimate of -1.12 is strongly statistically significant and suggests that failing AYP in 2003 led to about 1.1 fewer absences per teacher, on average, in 2004. From a base of 8.3, this represents a 13 percent decline in teacher absences.

The remainder of table 2 investigates the robustness of the baseline result to the functional form through which teacher absences enter the model. Because teacher absences are strictly nonnegative and zeros are exceedingly rare in the data, column 2 of table 2 estimates the baseline specification using the natural log of total teacher absences as the dependent variable. ${ }^{9}$ The log-specification DD estimate remains negative and strongly statistically significant. Specifically, the point estimate of -0.08 suggests that failing AYP is associated with an $8 \%$ decrease in teacher absences.

Finally, following Jacob (2013), columns 3-5 of table 2 report estimates of binary outcome models in which the dependent variable equals one if the teacher was absent 15 or more times, and zero otherwise. Column 3 presents OLS estimates of a Linear Probability Model (LPM) that is otherwise equivalent to the preferred baseline specification. The LPM estimate suggests that, on average, failing AYP decreased the probability of a teacher being absent 15 or more times by two percentage points, and this effect is statistically significant at the 5\% confidence level. From a base of $10 \%$, this represents a $20 \%$ decrease in teachers who were absent 15 or more times per school year. Importantly, this result suggests that the pressure associated with failing AYP drastically changed some teachers' attendance habits. Column 4 reports estimates of the same LPM for the restricted sample of schools that experienced variation

\footnotetext{
${ }^{9}$ Zeros are rare because many teachers have 0.5 annual absences, perhaps because of how an inservice professional development program was coded. In the log specification zeros were replaced with 0.5 , the smallest non-zero value observed in the data.
} 
in the dependent variable. It is reassuring that these estimates are nearly identical to those presented in column 3, as the FE (conditional) logit estimates reported in column 5 of table 2 that acknowledge the binary nature of the dependent variable make the same sample restriction (Wooldridge, 2010, p. 622). The FE-logit coefficient estimate reported in column 5 is negative and statistically significant at the $5 \%$ confidence level, but its magnitude cannot be directly compared to the LPM coefficients, nor can precise average partial effects (APE) be computed because values of the FE are unobserved (Wooldridge, 2010, p. 622). However, scaled coefficients that approximate APE, which can be compared to the LPM coefficients, can be computed using the product of the sample average of $\operatorname{Pr}(\mathrm{A}>15)(0.10)$ and one minus this probability (0.90) as an approximate scaling factor. The resulting scale factor of 0.09 implies an APE of about -0.023, which is in line with the LPM estimates reported above.

Overall, the results presented in table 2 provide consistent evidence that failing AYP in 2003 caused a significant decline in teacher absences (increase in effort) in 2004, regardless of how teacher absences are measured. Because the DD estimates condition on observable teacher characteristics, school FE, and time-varying observable school characteristics, the results are not driven by changes in the size or composition of schools' enrollments. Nonetheless, the next section presents a series of sensitivity analyses and falsification tests that further probe the robustness of the results and the plausibility of the DD assumptions.

To place the baseline estimates presented in table 2 in context, it is useful to compare them to the estimates of other interventions' effects on teacher absences. One relevant comparison is the effect of a change in policy in Chicago Public Schools during the early 2000s that decreased the job security of probationary teachers by increasing principals' ability to dismiss such teachers. Using a DD strategy similar to that employed in the current paper, Jacob 
(2013) finds that the policy change decreased teacher absences by about 1 absence per year, and decreased the probability that a teacher had 15 or more annual absences by about four percentage points. These point estimates are remarkably similar to those reported in table 2 , as are the estimated effects when converted to percentages. Similarly, Clotfelter et al. (2009) find that directly charging teachers $\$ 50$ per absence would reduce average annual absence rates by about one full absence. Finally, reducing the number of teachers who are absent more than 15 times per school year has arguably practically significant effects on student achievement: 10 teacher absences reduce math achievement by about 0.02 math score $\mathrm{SD}$, which is equivalent to replacing an average teacher with one from the bottom quintile of the effectiveness distribution (Clotfelter et al., 2009; Herrmann \& Rockoff, 2013).

\section{Sensitivity Analyses}

Table 3 reports a variety of sensitivity analyses designed to test the baseline DD estimate's robustness to a variety of modeling choices, assumptions, and estimation strategies. Columns 1 and 2 estimate augmented versions of the preferred baseline specification that control for unobserved teacher heterogeneity by conditioning on lagged absences and teacher FE, respectively. The lagged-absences DD estimate in column 1 is slightly smaller than the preferred baseline estimate, though it remains larger than one in magnitude and is strongly statistically significant. ${ }^{10}$ The two-way school and teacher FE DD point estimate reported in column 2 is statistically significant and similar in magnitude, though slightly larger, than the lagged-absences estimate shown in column $1 .^{11}$ The similarity between the lagged-absences and two-way FE

\footnotetext{
${ }^{10}$ The sample size in the lagged specification is smaller than in the main analytic sample because lagged absences are unobserved in teachers' first years of teaching.

${ }^{11}$ I use the two-way FE estimator proposed by Mittag (2012).
} 
estimates, and the fact that they straddle the preferred baseline estimate reported in column 1 of table 2, is reassuring given the bracketing property of the lagged and FE estimators (Angrist \& Pischke, 2009, p. 245). The similarities between the baseline estimate of -1.12 and the estimated effects in columns 1 and 2 of table 3 suggest that the baseline DD estimate is not biased by endogenous sorting of teachers into schools. Moreover, the teacher-FE estimate in column 2 suggests that the results are driven by within-teacher changes in behavior, as opposed to changes in the composition of "treated" schools' teaching staffs.

The estimates reported in columns 3 and 4 of table 3 provide further evidence that the effect is the result of changes in teachers' attendance habits and not the strategic shuffling of teachers across schools. First, column 3 of table 3 estimates the baseline model on a restricted "balanced panel" sample that excludes teachers who changed schools between 1997 and 2004. The resulting estimate is nearly identical to the preferred baseline estimate, again indicating that the threat of sanctions caused individual teachers to increase effort. Column 4 estimates a variant of the preferred baseline model that replaces the school FE with teacher FE, using the same "balanced" sample. School FE are redundant in this specification, as the sample is restricted to teachers who did not change schools. Once again, the point estimate is larger than one in magnitude and is statistically significant. The estimates reported in columns 3 and 4 of table 3 are consistent with the lagged-absence and two-way FE estimates reported in columns 1 and 2 and provide additional evidence that the baseline DD estimate is capturing the behavioral response of individual teachers and not changes in schools' faculties.

Another potential concern is that the baseline estimates are influenced by the behavior of outliers who are absent at extremely high rates, as high rates of absence are more likely to be associated with health issues than shirking (Jacob, 2013). Accordingly, column 5 of table 3 
reports estimates of the preferred baseline model on a restricted sample that excludes teachers who were absent 50 or more times in a given year. ${ }^{12}$ The resulting point estimate falls by about 20 percent, to -0.82 , but remains strongly statistically significant and is actually more precisely estimated than in the preferred baseline specification. Again, this result is consistent with the interpretation that the threat of sanctions caused a behavioral response in teacher attendance.

Finally, column 6 of table 3 shows that the main result is robust to excluding 2003 data from the analytic sample. This is reassuring, as the baseline estimate could be driven by an unobserved (to the econometrician) shock in 2003 caused schools to both fail AYP and experience an increase in teacher absences. ${ }^{13}$ That the baseline DD estimate is virtually unchanged when 2003 data is excluded from the analytic sample suggests that the results are not driven by endogenous flukes in the final pre-treatment year.

Table 4 explicitly probes the standard identifying assumptions of the DD estimator. The first assumption is that schools that failed AYP in 2003 were not simultaneously differentially affected by other policies or interventions that would affect teacher attendance in 2004. In North Carolina, the most plausible threat to this assumption is the state's pre-existing ABC accountability program, which was described in section 2.2. Previous research has argued that ABC performance measures are uncorrelated with AYP status (Ahn, 2013); ABC is therefore unlikely to confound the baseline DD estimates. Nonetheless, data on ABC classifications is readily available, which facilitates a straightforward test of this assumption. Specifically, I augment the baseline model to control for schools' ABC classification the previous year, which might affect teacher effort the following year. Because the ABC program began in 1997, 1997

\footnotetext{
${ }^{12}$ Qualitatively similar results are obtained using lower cutoffs (e.g., < 40 absences).

${ }^{13}$ For example, a particularly disruptive collection of students might have such effects. I thank an anonymous referee for suggesting this sensitivity analysis.
} 
data cannot be used in this analysis. Thus column 1 of table 4 estimates the baseline specification of equation (1) using only 1998-2004 data to provide context for interpreting the estimates presented in column 2, which result from the augmented version of (1) that conditions on schools' previous ABC classification. Recall from earlier that under ABC, schools receive one of four mutually exclusive designations. Thus, the model estimated in column 2 simply adds a set of $\mathrm{ABC}$ classification indicators to the specification shown in (1). Importantly, the estimated effects of failing AYP in 2003 on teacher absences reported in columns 1 and 2 of table 4 are strongly statistically significant and nearly identical in size to the preferred baseline DD estimate of -1.12 . These results suggest that the most likely simultaneous policy confounder, North Carolina's $\mathrm{ABC}$ accountability policy, is not biasing the preferred DD estimates.

The second crucial identifying assumption is the parallel slopes (i.e., common trends) assumption. Specifically, the consistency of the DD estimates hinges on there being no systematically different trends in teacher absences in schools that failed AYP in 2003 relative to schools that made AYP in 2003. Columns 3 and 4 of table 4 explicitly relax the parallel slopes assumption by estimating augmented versions of the preferred baseline model that condition on school-specific linear and quadratic time trends, respectively. The point estimates remain negative, larger than one in magnitude, and statistically significant in both instances. This suggests that the baseline estimates are not the result of pre-existing differential trends in treated schools. Rather, teachers in schools that failed AYP in 2003 experienced, on average, a negative 1.4 to 1.7 absence deviation from trend in the second year of NCLB.

Similarly, I test the parallel slopes assumption using an event study specification that interacts each of the year indicators with the treatment (failed AYP in 2003) indicator, which provides a direct test for the presence of preexisting differential trends in teacher absences in the 
schools that ultimately failed AYP in 2003. These estimates are reported in column 5 of table 4. It is reassuring, though unsurprising given the robustness of the school-trend models, that the pre-2004 placebo effects (interaction terms) are neither individually nor jointly statistically significant. Moreover, the placebo effects are uniformly small in magnitude $(<0.30)$ and display no clear patterns or trends, as half are positive, half are negative, and the magnitudes oscillate from year to year. The "true" treatment effect in 2004 remains statistically significant and larger than one in magnitude.

The stark difference between the true and placebo effects is more apparent visually, as shown in figure 1, where the effects (interaction terms) are plotted along with their $95 \%$ confidence intervals. Each of the placebo effects is small and their confidence intervals encompass zero, while the true effect stands out and its confidence interval does not contain zero. In sum, the robustness checks carried out in table 4 and depicted in figure 1 provide robust evidence of a statistically significant, negative, arguably causal effect of the threat of sanctions associated with failing AYP in the first year of NCLB on teacher absences in the subsequent year. Specifically, the results presented in table 4 provide strong evidence that the "parallel slopes" identifying assumption of the DD estimator is not violated, and hence that the DD estimates can be given a causal interpretation.

\section{Heterogeneous Treatment Effects}

There are a number of reasons why the increased accountability pressure associated with failing AYP in the first year of NCLB might elicit varied responses from different types of teachers. For example, teachers in high-stakes (i.e., tested) grades may feel greater pressure to increase student achievement on the end-of-grade tests used to compute proficiency rates (Fuller 
\& Ladd, 2013). In the analytic sample, grades 3 through 5 are tested and kindergarten, first grade, and second grade are not. The effect might also vary by observable teacher characteristics such as educational attainment, National Board Certification (NBC), experience, selectivity of undergraduate institution, and gender. Rationale for why the effect might vary by these characteristics is as follows. The first three characteristics all affect teacher pay scales in North Carolina. Because the cost of using sick days is loosely tied to earnings, and more strongly to experience, it is plausible that responses to increased accountability pressure vary by these characteristics. More generally, the training and experiences associated with these characteristics, and with attending a selective undergraduate institution, might make some teachers more resilient to changes in the work environment. Lastly, regarding gender, it is hypothesized that women are more sensitive to changes in accountability pressure. For example, previous research shows that changes in public sector sick leave and monitoring policies have larger effects on women than on men (De Paola et al., 2014), which could be attributable to either differences in home responsibilities or psychological differences (Bertrand 2011).

Column 1 of table 5 reports estimates of an augmented version of the baseline model that fully interacts the year, failed AYP, and yearxfailed AYP terms with these observable teacher characteristics. ${ }^{14}$ Because teacher characteristics vary within school-years, it is now possible to replace the school FE with school-by-year FE. These estimates are reported in column 2 of table 5. The school FE and school-by-year FE estimates are similar to one another, which is reassuring and again suggests that the main results are not driven by school-specific trends. None of the

\footnotetext{
${ }^{14}$ Models that include one source of heterogeneity at a time yield qualitatively similar results. Experience and the corresponding interaction terms are modeled linearly. However, the finding of no differential effects by experience is robust to modeling the interaction effect as a quadratic or cubic function in experience, and to instead using a "new teacher" binary indicator.
} 
interaction terms are statistically significant and as a whole the interaction terms are jointly insignificant.

Still, while insignificant at traditional confidence levels, the positive tested-grade interaction effect is interesting, as it suggests that the decrease in teacher absences documented to this point is stronger among teachers in low-stakes, non-tested grades. One possible explanation of this suggestive result is that the increased stress associated with teaching in a high-stress environment (e.g., Barksdale-Ladd \& Thomas, 2000; Daly \& Chrispeels, 2005; Fuller \& Ladd, 2013), which is associated with employee absences in other settings (Ose, 2005), is particularly acute in tested grades. The selective undergraduate institution interaction effect is similarly intriguing, as the selectivity of teachers' undergraduate institutions is weakly positively associated with student achievement gains (Boyd et al., 2008; Clotfelter et al., 2007; Rockoff et al., 2011), and suggests that teachers who attended selective undergraduate institutions experienced slightly larger decreases in absences (increases in effort) in response to failing AYP in 2003. We can only speculate as to the reason for this subtle difference, which could be attributable to the higher levels of cognitive and non-cognitive skills associated with selection into, and accumulated at, selective undergraduate institutions.

What might be of most interest to policy makers is how teachers' effort responds to the threat of sanctions across the distribution of teacher effectiveness. It is well known that the observable teacher qualifications discussed above explain, at best, only a small percentage of the total variation across classrooms in student achievement gains (e.g., Rockoff et al., 2011). Accordingly, as described in section 4, I directly estimate teachers' math value-added measures (VAMs) using matched student-teacher data. I then create a set of categorical indicators that identify which quartile of the VAM distribution each teacher falls in and once again estimate 
augmented versions of the baseline model that fully interact the year, failed AYP, and year $\times$ failed AYP terms with these categorical indicators of teacher effectiveness. Of course, VAMs are only available for teachers who taught in a tested grade in at least two years, so the VAM interaction specification can only be estimated on a subset of the baseline analytic sample.

Columns 3-5 of table 5 report three sets of estimates that rely on the subsample of teachers for whom VAM scores could be computed. Column 3 reports estimates of the preferred baseline model, which contains no interaction terms, to provide context. The DD point estimate is negative, slightly smaller than the preferred baseline estimate, and only marginally statistically significant. It is unsurprising that the point estimate is smaller, as tested-grade teachers comprise the majority of the subsample and the interaction specifications reported in columns 1 and 2 of table 5 suggest that the effect was smaller among tested-grade teachers. Moreover, the estimate's imprecision may owe to the substantially reduced sample size. Columns 4 and 5 of table 5 report estimates of the VAM-interaction models that condition on school and school-by-year FE, respectively. Like in the teacher-qualification interaction models, the two VAM interaction models yield qualitatively similar results. Also like in columns 1 and 2 of table 5, the interaction terms are both individually and jointly insignificant at traditional confidence levels. Moreover, there are no discernable patterns in the size of the effect across the teacher effectiveness distribution.

\section{CONCLUSIONS}

This paper estimates the effect of the threat of sanctions for failing to meet performance standards on employee effort in the public sector. The analysis exploits the fact that in the second year of NCLB, schools that failed to make AYP in the first year risked facing sanctions for 
failing to make AYP in two consecutive years. The results suggest that in year two of NCLB, teachers in schools that failed to make AYP in year one significantly reduced their annual absences by about $13 \%$, or a little more than one absence per year. Similarly, the probability that a teacher was absent 15 or more times fell by $20 \%$, or two percentage points, in such schools. The effect of NCLB's performance standards on teacher effort was mostly due to within-teacher changes in effort, as opposed to compositional changes in schools' teaching staffs.

These effects are arguably practically significant, as research on the harm associated with teacher absences in North Carolina finds that a one SD increase in teacher absences is associated with a decrease in math achievement of about 0.02 test-score SD, or $20 \%$ of the effect of a one SD increase in teacher effectiveness (Clotfelter et al., 2009; Herrmann \& Rockoff, 2012). The estimated effects of performance standards on teacher effort are consistent with previous research on the malleability of teacher effort, as Ahn (2013) and Jacob (2013) find evidence that teacher effort, as measured by teacher absences, responds to incentives. Indeed, the magnitudes of the estimated effects in the current paper are similar to those of the estimated effects of a policy change in Chicago that granted principals the discretion to dismiss probationary teachers (Jacob, 2013). Finally, it is worth noting that the estimates reported here likely underestimate the total effect of NCLB on teacher absences and teacher effort, as the policy placed pressure on all schools, including those that made AYP in the first year (Fuller \& Ladd, 2013).

The results of the current study have at least three implications for education policy. First, that teacher absences fell in response to increased accountability pressure suggests that one mechanism through which consequential accountability policies affect student achievement is through increased teacher effort. Second, these results contribute to the growing body of evidence that teacher effort, as measured by absences, responds to both school- and individual- 
level incentives. Finally, potential heterogeneity in teachers' responses to the threatened sanctions associated with failing AYP in the first year of NCLB suggest potential benefits to policy designs and teacher training programs that account for such differences. For example, to the extent that teachers in tested and non-tested grades responded differently to the threat of sanctions, standard labor-economic theory suggests that if jobs in tested grades are more stressful, such jobs can pay compensating differentials. The wage differentials need not be monetary and could instead be provided in the form of additional planning periods, teaching aids, or professional development. 


\section{REFERENCES}

Ahn, T. (2013). The missing link: Estimating the impact of incentives on teacher effort and instructional effectiveness using teacher accountability legislation data. Journal of Human Capital, 7(3), 230-273.

Ahn, T., \& J. Vigdor. (2014). The impact of No Child Left Behind's accountability sanctions on school performance: regression discontinuity evidence from North Carolina. NBER Working Paper No. w20511

Angrist, J. D., \& J. S. Pischke. (2008). Mostly harmless econometrics: an empiricist's companion. Princeton, NJ: Princeton University Press.

Barksdale-Ladd, M. A., \& K. F. Thomas. (2000). What's at stake in high-stakes testing teachers and parents speak out. Journal of Teacher Education, 51(5), 384-397.

Baker, E. L., P. E. Barton, L. Darling-Hammond, E. Haertel, H. F. Ladd, R. L. Linn, et al. (2010). Problems with the use of student test scores to evaluate teachers. Washington, DC: Economic Policy Institute.

Bertrand, M. (2011). New Perspectives on Gender. Handbook of Labor Economics, Vol. 4, ed. O. Ashenfelter and D. Card, 1543-1590. Amsterdam: North Holland.

Boyd, D., H. Lankford, S. Loeb, J. Rockoff, \& J. Wyckoff. (2008). The narrowing gap in New York City teacher qualifications and its implications for student achievement in highpoverty schools. Journal of Policy Analysis and Management, 27(4), 793-818.

Bradley, S., C. Green, \& G. Leeves. (2007). Worker absence and shirking: evidence from matched teacher-school data. Labour Economics, 14(3), 319-334.

Brummet, Q., S. Gershenson, \& M. Hayes. (2015). Teachers' grade-level reassignments: evidence from Michigan. In press, Educational Policy. 
Carnoy, M., \& S. Loeb. (2002). Does external accountability affect student outcomes? a crossstate analysis. Educational Evaluation and Policy Analysis, 24(4), 305-331.

Chakrabarti, R. (2014). Incentives and responses under No Child Left Behind: credible threats and the role of competition. Journal of Public Economics, 110, 124-146.

Clotfelter, C. T., H. F. Ladd, \& J. L. Vigdor. (2007). Teacher credentials and student achievement: longitudinal analysis with student fixed effects. Economics of Education Review, 26(6), 673-682.

Clotfelter, C. T., H. F. Ladd, \& J. L. Vigdor. (2009). Are teacher absences worth worrying about in the U.S.? Education Finance and Policy, 4(2), 115-149.

Clotfelter, C. T., H. F. Ladd, J. L. Vigdor, \& R. A. Diaz. (2004). Do school accountability systems make it more difficult for low-performing schools to attract and retain highquality teachers? Journal of Policy Analysis and Management, 23(2), 251-271.

Cullen, J. B., \& R. Reback. (2006). Tinkering toward accolades: School gaming under a performance accountability system. Improving School Accountability: Check-Ups or Choice? Advances in Applied Microeconomics, Vol. 14, ed. T. Gronberg and D. Jansen, 1-34. Amsterdam: JAI Press.

Daly, A. J., \& J. Chrispeels. (2005). From problem to possibility: leadership for implementing and deepening the process of effective schools. Journal for Effective Schools, 4, 7-25.

Das, J., S. Dercon, J. Habyarimana, \& P. Krishnan. (2007). Teacher shocks and student learning: evidence from Zambia. Journal of Human Resources, 42(4), 820-862.

Dee, T. S., \& B. Jacob. (2011). The impact of No Child Left Behind on student achievement. Journal of Policy Analysis and Management, 30(3), 418-446. 
De Paola, M., V. Scoppa, \& V. Pupo. (2014). Absenteeism in the Italian public sector: the effects of changes in sick leave policy. Journal of Labor Economics, 32(2), 337-360.

Duflo, E., R. Hanna, \& S. P. Ryan. (2012). Incentives work: getting teachers to come to school. American Economic Review, 102(4), 1241-78.

Feng, L., D. N. Figlio, \& T. Sass. (2010). School accountability and teacher mobility. NBER Working Paper No. 16070.

Figlio, D. N. (2006). Testing, crime and punishment. Journal of Public Economics, 90(4), 837851.

Figlio, D. N., \& L. W. Kenny. (2009). Public sector performance measurement and stakeholder support. Journal of Public Economics, 93(9), 1069-1077.

Figlio, D. N., \& H. F. Ladd. (2008). School accountability and student achievement. Handbook of Research in Education Finance and Policy, ed. H. F. Ladd and E. B. Fiske, 166-182. New York: Routledge.

Figlio, D., \& S. Loeb. (2011). School accountability. Handbook of the Economics of Education, Vol. 3, ed. E. Hanushek, S. Machin, and L. Woessmann, 383-421. Amsterdam: North Holland.

Fuller, S. C., \& H. F. Ladd. (2013). School-based accountability and the distribution of teacher quality across grades in elementary school. Education Finance and Policy, 8(4), 528-559.

Gaziel, H. H. (2004). Predictors of absenteeism among primary school teachers. Social Psychology of Education, 7(4), 421-434.

Gordon, N. (2008). The changing federal role in education finance and governance. Handbook of Research in Education Finance and Policy, ed. H. F. Ladd and E. B. Fiske, 295-313. New York: Routledge. 
Hansen, M. (2009). How career concerns influence public workers' effort: evidence from the teacher labor market. Calder Working Paper No. 40.

Hanushek, E. A. (1994). Making schools work: improving performance and controlling costs. Washington, DC: Brookings Institution Press.

Hanushek, E. A., \& M. E. Raymond. (2005). Does school accountability lead to improved student performance? Journal of Policy Analysis and Management, 24(2), 297-327.

Hanushek, E. A., \& S.G. Rivkin. (2010). Generalizations about using value-added measures of teacher quality. American Economic Review, 100(2), 267-271.

Imants, J., \& A. Van Zoelen. (1995). Teachers' sickness absence in primary schools, school climate and teachers' sense of efficacy. School Organization, 15, 77-87.

Heckman, J.J., C. J. Heinrich, \& J. Smith. (2011). Performance standards and the potential to improve government performance. The Performance of Performance Standards, ed. J. J. Heckman, 1-14. W.E. Upjohn Institute: Kalamazoo, MI.

Heinrich, C. J. (2007). False or fitting recognition? The use of high performance bonuses in motivating organizational achievements. Journal of Policy Analysis and Management, 26(2), 281-304.

Heinrich, C. J., \& G. Marschke. (2010). Incentives and their dynamics in public sector performance management systems. Journal of Policy Analysis and Management, 29(1), 183-208.

Herrmann, M. A., \& J. E. Rockoff. (2012). Worker absence and productivity: Evidence from Teaching. Journal of Labor Economics, 30(4), 749-782.

Hout, M., \& S. W. Elliott. (2011). Incentives and test-based accountability in education. Washington, DC: National Academies Press. 
Hoxby, C. M. (2007). The economics of school choice. Chicago, IL: University of Chicago Press.

Ichino, A., \& Maggi, G. (2000). Work environment and individual background: Explaining regional shirking differentials in a large Italian firm. The Quarterly Journal of Economics, 115(3), 1057-1090.

Jacob, B.A. (2005). Accountability, incentives and behavior: The impact of high-stakes testing in the Chicago Public Schools. Journal of Public Economics, 89, 761-796.

Jacob, B.A. (2013). The Effect of Employment Protection on Teacher Effort. Journal of Labor Economics, 31(4), 727-761.

Jacob, B.A., \& S. D. Levitt. (2003). Rotten apples: An investigation of the prevalence and predictors of teacher cheating. The Quarterly Journal of Economics, 118(3), 843-877.

Jacob, B.A., \& E. Walsh. (2011). What's in a rating? Economics of Education Review, 30(3), $434-448$.

Johansson, P., \& M. Palme. (1996). Do economic incentives affect work absence? Empirical evidence using Swedish Micro Data. Journal of Public Economics, 59(2), 195-218.

Ladd, H. F. (1996). Holding schools accountable: performance-based reform in education. Washington, DC: Brookings Institution Press.

Luna, C., \& C. L. Turner. (2001). The impact of the MCAS: Teachers talk about high-stakes testing. The English Journal, 91, 79-87.

Macartney, H. (2014). The dynamic effects of educational accountability. NBER Working Paper No. w19915. 
Miller, R., R. Murnane, \& J. Willett. (2008). Do teacher absences impact student achievement? Longitudinal evidence from one urban school district. Educational Evaluation and Policy Analysis, 30(2): 181-200.

Mittag, N. (2012). New methods to estimate models with large sets of fixed effects with an application to matched employer-employee data from Germany. FDZ-Methodenreport.

Ose, S. O. (2005). Working conditions, compensation and absenteeism. Journal of Health Economics, 24(1), 161-188.

Ost, Ben. (2014). How do teachers improve? The relative importance of specific and general human capital. American Economic Journal: Applied Economics, 6(2), 127-51.

Polikoff, M. S., \& S. L. Wrabel. (2013). When is $100 \%$ not $100 \%$ ? The use of safe harbor to make adequate yearly progress. Education Finance and Policy, 8(2), 251-270.

Reback, R., J. Rockoff, \& H. L. Schwartz. (2014). Under pressure: job security, resource allocation, and productivity in schools under NCLB. American Economic Journal: Economic Policy, 6(3), 207-41.

Rockoff, J. E., B. A. Jacob, T. J. Kane, \& D. O. Staiger. (2011). Can you recognize an effective teacher when you recruit one? Education Finance and Policy, 6(1), 43-74.

Rockoff, J. E., \& L. J. Turner. (2010). Short run impacts of accountability on school quality. American Economic Journal: Economic Policy, 2(4), 119-147.

Rouse, C. E., J. Hannaway, D. Goldhaber, \& D. Figlio. (2013). Feeling the Florida heat? How low-performing schools respond to voucher and accountability pressure. American Economic Journal: Economic Policy, 5(2), 251-281.

Roza, M. (2007). Frozen assets: rethinking teacher contracts could free billions for school reform. Education Sector Reports. 
Wooldridge, J.M. (2010). Econometric analysis of cross section and panel data, 2nd Ed.

Cambridge, MA: MIT Press. 
Table 1. Summary statistics for baseline analytic sample

\begin{tabular}{lcc}
\hline & $\begin{array}{c}\text { Full Sample } \\
(1)\end{array}$ & $\begin{array}{c}\text { VAM Sample } \\
(2)\end{array}$ \\
\hline Absences & 8.3 & 8.1 \\
SD & {$[9.0]$} & {$[8.6]$} \\
Within-school SD & {$[8.9]$} & {$[8.3]$} \\
Within-school-year SD & {$[8.5]$} & {$[7.3]$} \\
Within-teacher SD & {$[7.3]$} & {$[7.0]$} \\
15 or more absences & 0.10 & 0.10 \\
Failed AYP in 2003 & 0.46 & 0.46 \\
Tested Grade & 0.51 & 0.89 \\
Masters & 0.28 & 0.28 \\
Doctorate & 0.01 & 0.01 \\
Selective & 0.04 & 0.04 \\
National Board Certified & 0.11 & 0.14 \\
Experience & 13.6 & 13.1 \\
SD & {$[9.4]$} & {$[9.2]$} \\
Male & 0.03 & 0.06 \\
White & 0.82 & 0.82 \\
Black & 0.13 & 0.14 \\
Quartile 1 VAM & & 0.24 \\
Quartile 2 VAM & & 0.24 \\
Quartile 3 VAM & & 0.25 \\
Quartile 4 VAM & & 0.26 \\
N (Teacher Years) & 28,456 & 8,050 \\
Schools & 367 & 330 \\
\hline Not Tercher & &
\end{tabular}

Notes: Teacher-years are the unit of analysis. Standard deviations [SD] are reported in brackets for non-categorical variables. The analytic samples are restricted to teachers in Title-1 schools for whom the relevant teacher- and schoollevel data are available. $\mathrm{VAM}=$ math value added measure . 
Table 2. Baseline difference-in-difference estimates of effect of failing AYP

\begin{tabular}{lccccc}
\hline Model: & & Log & $1\{A>15\}$ & $1\{A>15\}$ & $1\{A>15\}$ \\
& Absences $(A)$ & Absences & LPM & LPM & FE Logit \\
& $(1)$ & $(2)$ & $(3)$ & $(4)$ & $(5)$ \\
\hline 2004×Failed & -1.12 & -0.08 & -0.02 & -0.02 & -0.26 \\
& $(0.35)^{* * *}$ & $(0.03)^{* * *}$ & $(0.01)^{* *}$ & $(0.01)^{* *}$ & $(0.12)^{* *}$ \\
Teacher-Years $(\mathrm{N})$ & 28,456 & 28,456 & 28,456 & 28,130 & 28,130 \\
Schools & 367 & 367 & 367 & 329 & 329 \\
$\mathrm{R}^{2}$ & 0.01 & 0.01 & 0.01 & 0.01 & 0.01 \\
\hline
\end{tabular}

Notes: Standard errors are clustered by school. All models condition on school and year fixed effects (FE), time-varying observed school characteristics, and observed teacher characteristics. Column 4 reports linear probability model (LPM) estimates on the FE logit sample. Column 5 reports the FE Logit coefficient estimate. The conditional FE Logit estimator drops clusters (schools) for which there is no variation in the dependent variable. $1\{$.$\} is the indicator function. Column 5$ reports McFadden's Pseudo $\mathbf{R}^{2}$. $* * * \mathrm{p}<0.01, * * \mathrm{p}<0.05, * \mathrm{p}<0.1$. 
Table 3. Sensitivity analyses of effect of failing AYP on teacher absences

\begin{tabular}{lcccccc}
\hline Specification: & $\begin{array}{c}\text { Lagged } \\
\text { Absences }\end{array}$ & $\begin{array}{c}\text { 2-way } \\
\text { Teacher \& } \\
\text { School FE }\end{array}$ & $\begin{array}{c}\text { Balanced } \\
\text { Panel }\end{array}$ & $\begin{array}{c}\text { Balanced } \\
\text { Panel, } \\
\text { Teacher FE } \\
(1)\end{array}$ & $\begin{array}{c}<50 \text { Abs. } \\
\text { Sample } \\
\text { Restriction }\end{array}$ & $\begin{array}{c}\text { Exclude } \\
\text { 2003 Data }\end{array}$ \\
\hline 2004×Failed & -1.09 & -1.18 & -1.12 & -1.05 & -0.82 & $(6)$ \\
& $(0.41)^{* * *}$ & $(0.47)^{* *}$ & $(0.37)^{* * *}$ & $(0.41)^{* *}$ & $(0.28)^{* * *}$ & $(0.37)^{* * *}$ \\
Adjusted $\mathrm{R}^{2}$ & 0.02 & 0.11 & 0.01 & 0.01 & 0.01 & 0.01 \\
$\mathrm{~N}$ & 20,177 & 28,456 & 24,096 & 24,096 & 28,220 & 24,706 \\
Schools & 344 & 367 & 362 & 362 & 367 & 366 \\
\hline Controls & Yes & Yes & Yes & Yes & Yes & Yes \\
School FE & Yes & Yes & Yes & No & Yes & Yes \\
Teacher FE & No & Yes & No & Yes & No & No \\
\hline
\end{tabular}

Notes: Standard errors are clustered by school. All models condition on year fixed effects (FE), timevarying observed school characteristics, and observed teacher characteristics. The sample restriction and inclusion of teacher FE in column 4 make school FE redundant in this specification. The balanced panels in columns 3 and 4 exclude teachers who changed schools between 1997 and 2004. $* * * \mathrm{p}<0.01, * * \mathrm{p}<0.05, * \mathrm{p}<0.1$. 
Table 4. Tests of the difference-in-difference estimator assumptions

\begin{tabular}{|c|c|c|c|c|c|}
\hline Specification: & $\begin{array}{c}\text { ABC } \\
\text { Sample } \\
(1)\end{array}$ & $\begin{array}{c}\text { ABC } \\
\text { Sample } \\
(2)\end{array}$ & $\begin{array}{l}\text { Linear } \\
\text { School } \\
\text { Trends } \\
\text { (3) }\end{array}$ & $\begin{array}{c}\text { Quadratic } \\
\text { School } \\
\text { Trends } \\
\text { (4) }\end{array}$ & $\begin{array}{c}\text { Event Study } \\
\text { (5) }\end{array}$ \\
\hline \multicolumn{6}{|l|}{ Lagged ABC Status } \\
\hline Low Performing & & $\begin{array}{l}-0.73 \\
(0.47)\end{array}$ & & & \\
\hline No Recognition & & (omitted) & & & \\
\hline Expected Growth & & $\begin{array}{c}0.14 \\
(0.19)\end{array}$ & & & \\
\hline High Growth & & $\begin{array}{c}-0.06 \\
(0.18)\end{array}$ & & & \\
\hline $1998 \times$ Failed & & & & & $\begin{array}{c}0.23 \\
(0.38)\end{array}$ \\
\hline $1999 \times$ Failed & & & & & $\begin{array}{l}-0.28 \\
(0.42)\end{array}$ \\
\hline 2000×Failed & & & & & $\begin{array}{l}-0.08 \\
(0.46)\end{array}$ \\
\hline $2001 \times$ Failed & & & & & $\begin{array}{l}-0.11 \\
(0.43)\end{array}$ \\
\hline $2002 \times$ Failed & & & & & $\begin{array}{c}0.15 \\
(0.44)\end{array}$ \\
\hline $2003 \times$ Failed & & & & & $\begin{array}{c}0.29 \\
(0.46)\end{array}$ \\
\hline 2004×Failed & $\begin{array}{c}-1.16 \\
(0.36) * * *\end{array}$ & $\begin{array}{c}-1.15 \\
(0.36) * * *\end{array}$ & $\begin{array}{c}-1.37 \\
(0.42)^{* * *}\end{array}$ & $\begin{array}{c}-1.65 \\
(0.65)^{* *}\end{array}$ & $\begin{array}{c}-1.07 \\
(0.48)^{* *}\end{array}$ \\
\hline Adjusted $\mathrm{R}^{2}$ & 0.01 & 0.01 & 0.03 & 0.03 & 0.01 \\
\hline $\mathrm{N}$ & 24,538 & 24,538 & 28,456 & 28,456 & 28,456 \\
\hline Schools & 363 & 363 & 367 & 367 & 367 \\
\hline
\end{tabular}

Notes: Standard errors are clustered by school. All models condition on school and year fixed effects (FE), time-varying observed school characteristics, and observed teacher characteristics. The ABC sample used in columns 1 and 2 excludes observations from the 1997 school year. The set of ABC status indicators included in column 2 represent the school's ABC status in the previous year. $* * * \mathrm{p}<0.01, * * \mathrm{p}<0.05, * \mathrm{p}<0.1$. 
Table 5. Heterogeneity in effects of failing AYP on teacher absences

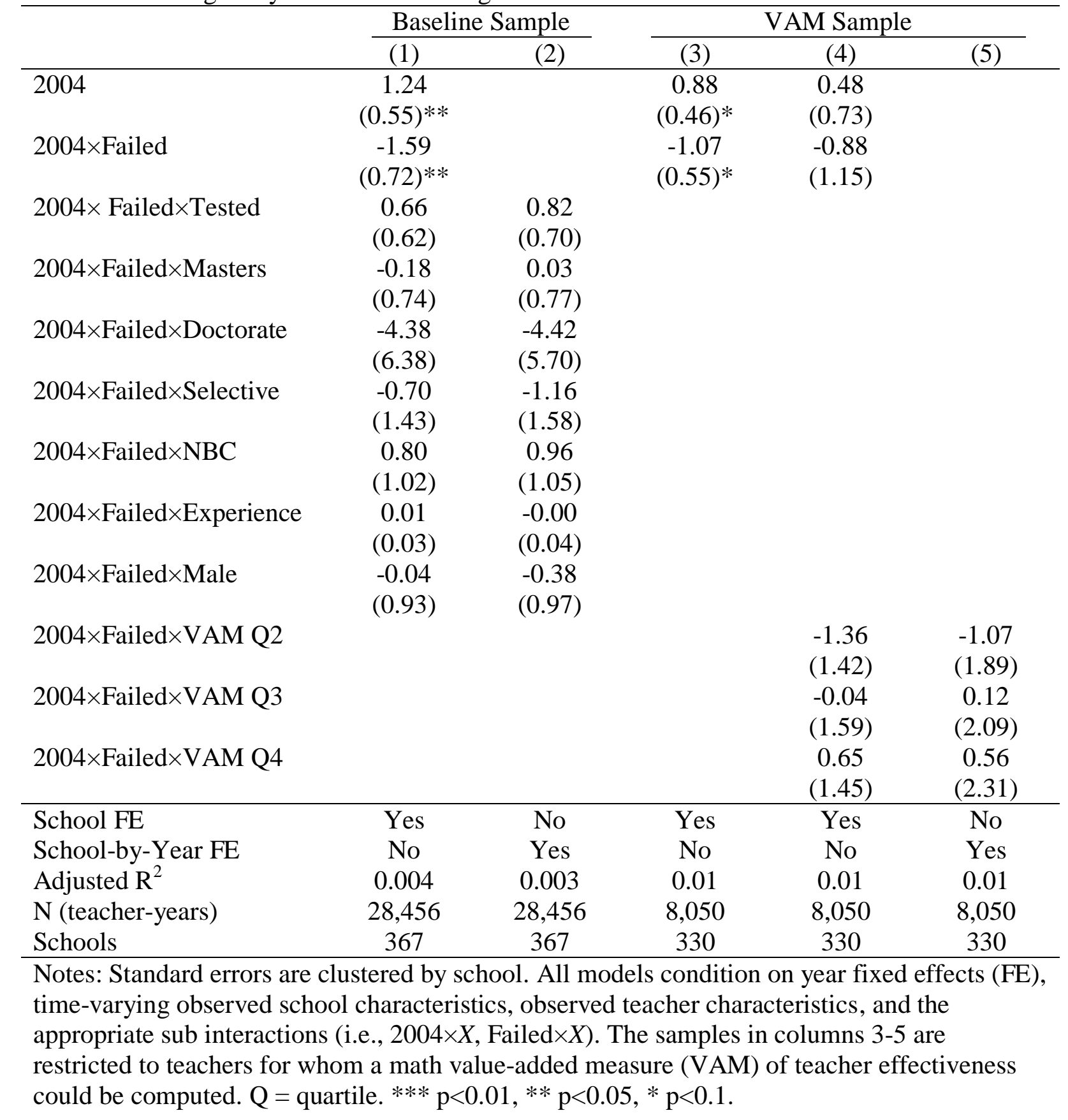


Figure 1. Event study estimates

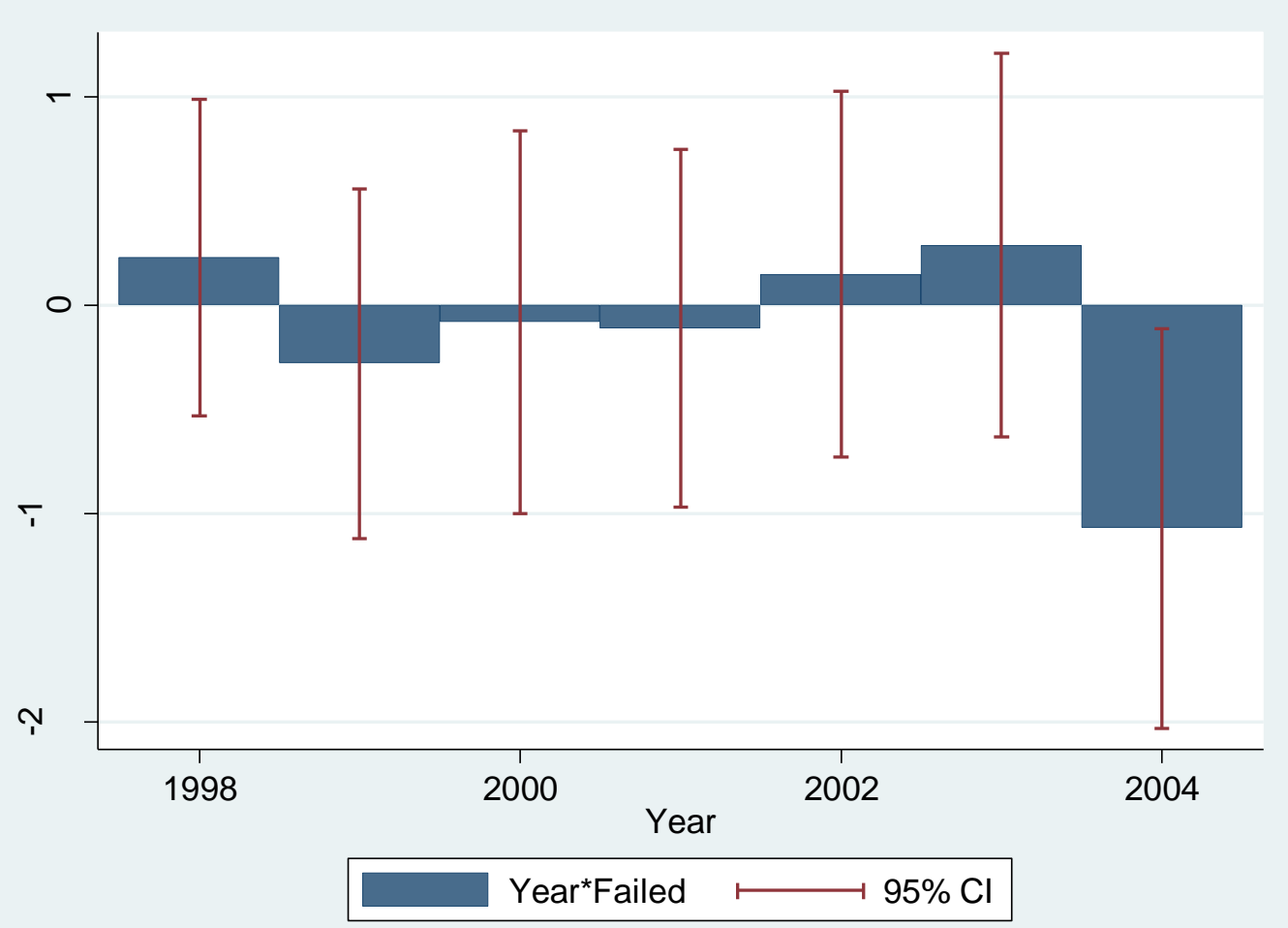

Notes: 95\% Confidence intervals (CI), which are robust to clustering at the school level, are reported. These estimates correspond to the point estimates reported in column 5 of table 4 . 


\section{Online Appendix}

\section{Performance Standards and Employee Effort: Evidence from Teacher Absences}

\section{Online Appendix A: Theoretical Model of Absences as a Labor Supply Decision}

As discussed in the introduction, the direction of the effect of accountability pressure on teacher absences is theoretically ambiguous. Some teachers relish the opportunity to improve student performance and increase effort in response to accountability pressure, if for no other reason than to avoid the negative consequences of failing to make AYP (Figlio \& Loeb, 2011). Others might be encouraged to reduce absences by their principals or fellow teachers. Not all teachers necessarily respond this way, however, as high-stakes testing decreases teachers' classroom autonomy and sense of job security (Reback et al., 2014) and increases teachers' stress levels (Barksdale-Ladd \& Thomas, 2000; Daly \& Chrispeels, 2005). The Pain Reduction Model suggests that employees might respond to these reductions in job satisfaction by using absences to avoid work (Gaziel, 2004). These intuitive arguments can be formalized by viewing employees' daily attendance (i.e., absence) decisions as daily labor-supply decisions.

Assume that teachers maximize expected utility when making daily attendance decisions. Then teachers' optimal behavior is governed by a simple "reservation wage" decision rule (Bradley et al., 2007; Gershenson, 2012). Formally, teacher $i$ chooses to work on day $d$ if the expected utility of working $\left(U_{i d}^{W}\right)$ exceeds the expected utility of being absent $\left(U_{i d}^{A}\right)$, and is absent otherwise. Assuming that these daily utilities contain additively-separable stochastic terms, the probability that teacher $i$ is absent on day $d$ is

$$
\operatorname{Pr}\left(a_{i d}=1\right)=\operatorname{Pr}\left(U_{i d}^{A} \geq U_{i d}^{W}\right)=G\left(U_{i d}^{A}-U_{i d}^{W}\right),
$$

where $G$ is the CDF of the distribution of the difference between the two stochastic components of daily utility, as in the standard random utility model (Cameron \& Trivedi, 2005, p. 477). 
In expectation, then, teacher $i$ 's total annual absences $(A)$ are simply

$$
E\left(A_{i}\right)=\sum_{d} G\left(U_{i d}^{A}-U_{i d}^{W}\right) .
$$

Assume that $U^{W}$ is decreasing in hours worked $(H)$ and that the disutility associated with teaching $(\Psi)$ is increasing in accountability pressure $(p)$. Additionally, assume that $U^{A}$ is decreasing in $p$ due to the negative relationship between teacher absences and student achievement, principal preferences for teacher attendance, and teachers' preferences to work in non-failing schools. Straightforward application of the chain rule shows that the direction of the effect of $p$ on teacher absences is ambiguous. ${ }^{15}$ Formally,

$$
\frac{\delta E(A)}{\delta p}=\sum_{d} G^{\prime}(\cdot)\left(\frac{\delta U^{A}}{\delta p}-\frac{\delta U^{W}}{\delta \psi} \cdot \frac{\delta \psi}{\delta p}\right)
$$

where $G^{\prime}$ is strictly positive and the second term on the RHS of (3) is positive if and only if $\frac{\delta U^{A}}{\delta p}>\frac{\delta U^{W}}{\delta \psi} \frac{\delta \psi}{\delta p}$. Intuitively, the direction of the net effect depends on the relative sizes of the "incentive" and "disutility" effects (i.e., the marginal effects of $p$ on the costs and benefits of being absent). Note that the sign of (A3) is ambiguous even under the strong assumption that teachers' preferences are constant across days; daily fluctuations in preferences provide an additional potential source of ambiguity.

\footnotetext{
${ }^{15}$ See Blundell \& MaCurdy (1999) and Stern (1986) for descriptions of utility functions that incorporate the disutility of working and their corresponding labor supply functions. Two common examples are the Frisch and Stone-Geary functional forms.
} 


\section{Online Appendix B: Regression Discontinuity (RD) Sensitivity Analysis}

As mentioned in section 2.3 of the main text, previous research has investigated the effect of failing AYP on student achievement using regression discontinuity (RD) designs that exploit schools' "closeness" to the AYP threshold (e.g., Ahn \& Vigdor, 2014; Chakrabarti, 2014). A similar strategy could be employed in the context of the current study, which would rely on a school-specific running variable $(c)$ that measures the school's closeness to making AYP in 2003. In 2003, there were no waivers or "safe harbor" exemptions. In North Carolina, schools must make AYP both overall and in student subgroups that contain 40 or more students. Subgroups are Asian/Pacific Islander, Black, Hispanic, Multi-racial, Native American, White, Economically Disadvantaged, Limited English Proficient, and Students with Disability. If any subgroup's proficiency rate does not meet the threshold defined by the state, the school fails to make AYP. North Carolina's primary school math and reading proficiency thresholds in 2003 were $74.6 \%$ and $68.9 \%$, respectively. Thus, following Ahn and Vigdor (2014), I define $c$ as the minimum within-school difference between the actual proficiency rate of each subgroup and the state's AYP threshold. Proficiency rates are taken from data compiled by Reback et al. (2014), which the authors generously make publicly available here: http://www8.gsb.columbia.edu/nclb/.

After creating $c$, I estimate a "simple" fuzzy-RD design by 2 SLS (Angrist \& Pischke, 2009, p. 261) using all 2004 data on teacher absences. Specifically, the first stage is

$$
\text { Failed }_{i s}=\pi_{0}+\pi_{1} c_{s}+\pi_{2} X_{i s}+\pi_{3} T_{s}+\xi_{i s},
$$

where $T$ is a binary indicator equal to one if $c<0$, and zero otherwise. The first stage results provide no evidence of a weak instruments problem. The second stage is then

$$
A_{i s}=\beta_{0}+\beta_{1} c_{s}+\beta_{2} X_{i s}+\tau \text { Failed } 03_{s}+\varepsilon_{i s} .
$$


The "simple" fuzzy-RD estimate of $\tau$, the effect of just failing AYP in 2003 on 2004 absences, is -1.09. This point estimate is right in line with the preferred DD estimates reported in tables 2,3 , and 4 of the main text. However, the RD estimate is insignificant at traditional confidence levels (standard error $=0.97$ ), which is perhaps unsurprising given the relative lack of precision associated with 2SLS estimation and RD designs more generally. I discuss the "simple" fuzzy$\mathrm{RD}$ estimate here because it is relatively transparent and has good finite sample properties (Angrist \& Pischke, 2009, p. 261). However, a variety of alternative specifications were also considered: including polynomials in $c$, allowing the slope to vary for positive and negative values of $c$, excluding $X$ from the model, conditioning on school-district FE, and trimming schools with high and low values of $c$ from the analytic sample. These alternative specifications generally yield estimates of $\tau$ in range of -0.5 to -2.5 , none of which are statistically significant at traditional confidence levels, regardless of whether the standard errors are clustered by school, district, or not at all.

Another potential use of the running variable $c$, which is in the spirit of the "discontinuity sample" sensitivity analysis advocated by Angrist \& Pischke (2009, p. 257), is to estimate the baseline DD specification on a restricted sample of schools that were "close" to the AYP threshold in 2003. Doing so yields statistically significant estimates of about -1 , which suggests that the main results are not driven by extremely high- or low-performing schools. For example, restricting the sample to schools in the $10^{\text {th }}-90^{\text {th }}$ and $25^{\text {th }}-75^{\text {th }}$ interpercentile ranges of $c$ yields statistically significant point estimates of -1.11 and -0.98 , respectively. Together, these RDflavored sensitivity analyses suggest that the main results are not driven by schools in the tails of the "AYP likelihood" distribution, and highlight the importance of conditioning on school FE in the baseline DD specification. 


\section{Online Appendix C: Value Added Measures (VAMs) of Teacher Effectiveness}

Following Gershenson (2015) and Jackson (2013), value-added measures of teacher effectiveness are generated by value-added models of the form

$$
y_{i j g s t}=\alpha y_{i, t-1}+\boldsymbol{\beta} \mathbf{x}_{i t}+\gamma \mathbf{c}_{-i, j g s t}+\theta_{j}+\pi_{g}+\omega_{s t}+u_{i j g s t},
$$

where $i, j, g, s$, and $t$ index students, teachers, grades, schools, and years, respectively; $y$ is performance on the end-of-grade math test, which is standardized by grade and year to have mean zero and standard deviation one (Ballou, 2009); $\mathbf{x}$ is a vector of observed student characteristics including race, gender, poverty status, special education, and English language proficiency; $\mathbf{c}$ is a vector of classroom characteristics including class size, class composition, and the average of student $i$ 's classmates' lagged achievement (peer effects); $\theta, \pi$, and $\omega$ are teacher, grade, and school-by-year fixed effects (FE), respectively; and $u$ is an idiosyncratic error term.

Equation (C1) is estimated by Ordinary Least Squares for two reasons. First, Guarino, Reckase, and Wooldridge (2015) find OLS to be the most robust estimator to a variety of potential student-teacher assignment scenarios. This is potentially important, as Rothstein (2010) finds evidence of non-random sorting in North Carolina. Second, Chetty et al. (2014) find that most sorting of students to teachers is based on lagged test scores and that conditioning on lagged test scores alone yields estimated teacher effects with near-zero bias. Similarly, Kane and Staiger (2008) find that controlling for lagged test scores yields unbiased estimates of teacher effects and that controlling for classroom characteristics (i.e., the vector c) improves the precision of estimated teacher effects.

Equation (C1) is estimated using student-level data on more than $1,112,000$ fourth and fifth grade students and more than 32,000 fourth and fifth grade teachers between the years 2004 and 2010, as third-grade and 2003 data are lost in the creation of lag scores. Note that a VAM 
can be estimated for a teacher who did not teach in a tested grade in 2004, so long as the teacher did teach in a tested grade in at least two years during this time span. The estimated teacher effects are strongly jointly significant $(\mathrm{F}=4.5)$ and the standard deviation of estimated teacher effects is 0.48 . Estimated teacher effects range from -3.38 to 2.13. Quartiles of the full distribution of estimated teacher effects are $-0.28,0.06$, and 0.29 . 


\section{Online Appendix References}

Ahn, T., \& Vigdor, J. (2014). The impact of No Child Left Behind's accountability sanctions on school performance: regression discontinuity evidence from North Carolina. NBER Working Paper No. w20511

Angrist, J. D., \& Pischke, J. S. (2008). Mostly harmless econometrics: An empiricist's companion. Princeton University Press.

Ballou, D. (2009). Test scaling and value-added measurement. Education Finance and Policy, 4(4), 351-383.

Barksdale-Ladd, M. A., \& Thomas, K. F. (2000). What's at Stake in High-Stakes Testing Teachers and Parents Speak Out. Journal of Teacher Education, 51(5), 384-397.

Blundell, R., \& MaCurdy, T. (1999). Labor supply: A review of alternative approaches. In (eds.), Handbook of Labor Economics, vol. 3A, (pp. 1559-1695) Amsterdam: North Holland.

Bradley, S., Green, C., \& Leeves, G. (2007). Worker absence and shirking: Evidence from matched teacher-school data. Labour Economics, 14(3), 319-334.

Cameron, A. C., \& Trivedi, P. K. (2005). Microeconometrics: methods and applications. Cambridge university press.

Chakrabarti, R. (2014). Incentives and responses under No Child Left Behind: Credible threats and the role of competition. Journal of Public Economics, 110, 124-146.

Chetty, R., J.N. Friedman, and J.E. Rockoff. (2014). Measuring the impacts of teachers I: Evaluating bias in teacher value-added estimates. American Economic Review, 104(9), 25932632.

Daly, A. J., \& Chrispeels, J. (2005). From problem to possibility: Leadership for implementing and deepening the process of effective schools. Journal for Effective Schools, 4, 7-25.

Figlio, D., \& Loeb, S. (2011). School accountability. In E. Hanushek, S. Machin, \& L. Woessmann (Eds.), Handbook of the Economics of Education, vol. 3, (pp. 383-421). Amsterdam: North Holland.

Gaziel, H. H. (2004). Predictors of absenteeism among primary school teachers. Social Psychology of Education, 7(4), 421-434.

Gershenson, S. (2012). How do substitute teachers substitute? An empirical study of substituteteacher labor supply. Economics of Education Review, 31(4), 410-430.

Gershenson, S. (2015). Linking teacher quality, student attendance, and student achievement. Education Finance and Policy. In Press. 
Guarino, C. M., M. D. Reckase, and J. M. Wooldridge. (2015). Can value-added measures of teacher performance be trusted? Education Finance and Policy, 10(1), 117-156.

Jackson, C. K. (2013). Non-cognitive ability, test scores, and teacher quality: Evidence from 9th grade teachers in North Carolina. NBER Working Paper No. w18624.

Kane, T. J., and D.O. Staiger. (2008). Estimating teacher impacts on student achievement: An experimental evaluation. NBER Working Paper No. w14607.

Reback, R., J. Rockoff, \& Schwartz, H. L. (2014). Under pressure: Job security, resource allocation, and productivity in schools under NCLB. American Economic Journal: Economic Policy, 6(3), 207-41.

Rothstein, J. (2010). Teacher quality in educational production: Tracking, decay, and student achievement. Quarterly Journal of Economics 125(1), 175-214.

Stern, Nicholas (1986) On the specification of labour supply functions. In: Blundell, Richard and Walker, Ian, (eds.) Unemployment, Search and Labour Supply. Cambridge University Press, Cambridge, UK, pp. 143-189. 